\title{
VIABILIDADE DO USO DA ADUBAÇÃO VERDE NOS AGROE COSSISTEMAS DA REGIÃO DE SÃO CARLOS, SP(1)
}

\author{
L. F. G. PINTO(2) \& S. CRESTANA(3)
}

\begin{abstract}
RESUMO
De modo geral, os sistemas de produção agrícola têm levado os agroecossistemas a uma grande instabilidade, acarretando forte degradação ambiental. Este trabal ho visa estudar o potencial da utilização de adubação verde na região de São Carlos (SP) como uma técnica complementar aos sistemas de produção ora existentes, buscando alcançar um incremento qualitativo de seus agroecossi stemas. A delimi tação da região estudada baseou-se em características climáticas, geomorfológicas e admi nistrativas, a partir de informações oriundas de mapas temáticos, manipulados por meio de um sistema de informações geográficas (SIG). A unidade de planejamento agroecológico para a região de São Carlos é constituída pelos municípios de Analândia, Itirapina, Santa Maria da Serra, São Carlos, São Pedro e Torrinha. Na região, descreveram-se o clima e os tipos de solo, tendo sido estes últimos agrupados de acordo com suas respectivas texturas e fertilidades. A partir disto, gerou-se um mapa com as zonas edáficas, predomi nantemente álicas e de textura arenosa. Paralelamente, foram listadas espécies de adubo verde com ecofisiologia compatível com as características edafoclimáticas encontradas, agrupando tais espécies em três classes: exigentes, rústicas e muito rústicas. Finalmente, elaborou-se um mapa com as zonas de cultivo de cada grupo de espécies. Concluiu-se que a adubação verde é uma técnica com potencial para melhorar a qualidade dos agroecossistemas da região de São Carlos.
\end{abstract}

Termos de indexação: adubação verde, agroecossistemas, sistema de informações geográficas.

(1) Parte da Tese de Mestrado em Ciências da Engenharia Ambiental do primeiro autor, apresentada à Escola de Engenharia de São Carlos, Universidade de São Paulo. Trabalho apresentado no XIII Congresso Latino Americano - Solo Suelo, Águas de Lindóia, 1996. Pesquisa financiada parcialmente pelo projeto EMBRAPA 12.0.94.093. Recebido para publicação em setembro de 1997 e aprovado em abril de 1998.

(2) Pesquisador do Instituto de Manejo e Certificação Florestal e Agrícola. Av. Carlos Botelho, 853. CEP $13416-145$ Piracicaba (SP). E-mail: imaflora@am.esalq.usp.br.

(3) Pesquisador, PhD, da EMBRAPA - Centro Nacional de Pesquisa e Desenvolvimento de Instrumentação Agropecuária. Caixa Postal 741. CEP 13560-970 São Carlos (SP). E-mail: crestana@cnpdia.embrapa.br 


\title{
SUMMARY: GREEN MANURE VIABILITY USE IN THE AGROECOSYSTEM OF THE SÃO CARLOS-SP REGION
}

\begin{abstract}
In general, farming systems have contributed to highly unstable conditions in agroecosystems, resulting in severe environmental degradation. The present study ai ms to verify the potential of green manure usein theSão Carlos region (SP), as a complementary techniqueto cropping systems present in the region under investigation, with theobjective of improving the quality of its agroecosystems. The region was delimited based on its dimate, geomorphol ogy and admi nistrativecharacteristics, obtained from basic maps and handled through a Geographic Information System. The agroecological planning unit of the São Carlos region is composed of Analândia, Itirapina, Santa Maria da Serra, São Carlos, São Pedro and Torrinha counties. The climate and soils of the region were described with the soils grouped according to their fertilities and textures. A map was produced with theE daphic zones of this area, identifying mainly sandy and alic classes. A listing was made of green manure plant species having ecophisiology compatible with the local edaphoclimate characteristics and these species were grouped into three classes: demanding, rustic and very rustic. Finally, a map was produced with thecultivation zones of each group of species. It can beconcluded that green manureis a techniquewith great potential for improving the quality of the agroecosystem of the studied area.
\end{abstract}

Index terms: Agroecosystem, Geographic Information System, gren manure

\section{INTRODUÇÃO}

O agroecossistema deve ser entendido como o ecossistema de maior importância para a espécie humana, por fornecer alimento e matéria-prima, elementos essenciais para a sobrevivência do homem, ocupando 30\% da superfície terrestre continental, Elli ot \& Cole (1989). Todavia, em função dos model os adotados e das técnicas aplicadas aos agroecossistemas dominantes no mundo, estes têm causado sérios impactos ambientais, como desmatamento, degradação e contaminação dos sol os e recursos hídricos.

Esse cenário de degradação ambiental deve ser alterado através da compatibilização da atividade agrícol a com o conceito de desenvol vimento sustentável. A agricultura sustentável pode ser entendida do ponto de vista filosófico, envolvendo nova visão de model o de desenvol vimento, ou pode ser abordada através da pesquisa e utilização de tecnologias apoiadas em bases sustentáveis, Hansen (1996).

Dessa forma, Pinto (1996) argumenta que a compatibilização entre desenvolvimento sustentável e agricultura deve ser alcançada através do diagnóstico dos agroecossistemas existentes, do planejamento do uso da terra e da formulação de sistemas de produção e técnicas que respeitem as características naturais, culturais e sócio-econômicas locais. Finalmente, todo esse processo deve considerar a viabilidade econômica da atividade.

No planejamento agrícola regional,devem-se levantar o potencial do meio físico e a aptidão ecológica de uma região, sendo necessário considerar, conjuntamente, os elementos do clima (aptidão climática) e do solo (aptidão edáfica). Os elementos do clima são, comumente, muito mais generalizados, abrangendo áreas extensas. Por essa razão, os trabalhos de zoneamento ecológico iniciam-se pelo zoneamento climático, introduzindo-se, em seguida, os el ementos do fator edáfico, em geral mais variados e desuniformes no espaço geográfico, Camargo et al . (1974).

Sistemas de Informações Geográficas (SIG), programas e modelos computacionais têm sido apresentados como ferramentas importantes para a realização do diagnóstico e do planejamento agrícola e ambiental. Através de manipulações de imagens e simulações de cenários, têm-se obtido importantes resultados, que orientam a atividadeem si e a própria pesquisa, possibilitando a otimização de recursos e tempo, Star \& Estes (1990).

Gonçal ves et al. (1991), discutindo a ocupação das terras da região de São Carlos (SP), indicam a pequena e má utilização dessas terras, decorrente da baixa fertilidade de seus solos, do relevo relativamente acidentado e da falta de técnicas adaptadas a tais características. Trata-se de uma regiãocom potencial para a atividade agrícola, porém apresenta características naturais que restringem tal atividade e potencializam seus impactos sobre o ambiente. Sugere-se, então, a realização de novos trabalhos sobre o uso dessas terras, o que poderia melhorar o seu índice de aproveitamento e, possivelmente, diminuir a agressão ao meio ambiente, associado a um aumento da produtividade. 
O manejo do solo e da matéria orgânica influencia tanto os rendimentos obtidos na produção agrícola como a qualidade ambiental, Pinto \& Crestana (1996). Segundo Calegari (1993), a adubação verde se destaca entre as técnicas sustentáveis que procuram otimizar o aproveitamento e os benefícios da matéria orgânica. Essa técnica visa à proteção superficial do solo, bem como à melhoria e manutenção de suas características físicas, químicas e biológicas. Dessa forma, a adubação verde constitui um conjunto de ações integradas quetrazem grandes benefícios aos solos e sistemas agrícolas em geral, como, por exemplo: proteção do solo contra erosão; el evação da taxa de infiltração e aumento da capacidade de retenção de água; recuperação da estrutura; adição de matéria orgânica; aumento da CTC; promoção do aumento do teor de nitrogênio; controle de nematóides; aumento e diversificação da população de microrganismos do solo, incremento da capacidade de reciclagem e mobilização de nutrientes lixiviados ou pouco solúveis em camadas mais profundas do solo.

A escol ha de espécies e o planejamento do uso da adubação verde devem seguir alguns critérios. Bulisani \& Roston (1993) destacam as características ecofisiológicas das espécies utilizadas como fatores limitantes à implantação e desenvolvimento do sistema, razão por que os principais fatores a serem considerados devem ser temperatura, fertilidade dos sol os e disponibilidade de água.

Nesta perspectiva, os objetivos deste trabalho foram realizar a caracterização edafoclimática da região de São Carlos (SP) e estudar o potencial da utilização da adubação verde nesta região como uma técnica complementar aos seus sistemas de produção, visando incrementar a qual idade dos seus agroecossistemas.

\section{MATERIAL E MÉTODOS}

De acordo com método apresentado por Camargo et al. (1974), delimitou-se a Zona Agroecológica da região de São Carlos com base nas características de clima e geomorfologia com análise posterior dos solos da região estudada.

Para tanto, foram utilizados os seguintes mapas temáticos: a) I sotermas anuais do Estado de São Paulo, Instituto Agronômico de Campinas (IAC), escala 1:2.000.000; b) Deficiência hídrica anual do Estado de São Paulo, IAC, 1:2.000.000; c) Divisões geomorfológicas do Estado de São Paulo, Instituto de Pesquisa Tecnológica, 1:500.000; d) Divisão municipal e distrital do Estado de São Paulo, Instituto Geográfico e Cartográfico de São Paulo, 1:2.000.000; e) Caracterização pedológica do Estado de São Paulo, IAC, 1:100.000, quadrículas Descalvado, São Carlos, Piracicaba e Brotas.
Em cada mapa, foram identificadas as unidades representativas e homogêneas da região de São Carlos, visando delimitar áreas com características exdusivas.

Do mapa a, digitalizou-se a isoterma anual de valor $20-21^{\circ} \mathrm{C}$; domapa b, a isol inha de val or $20-40 \mathrm{~mm}$, e do mapa c, a região das Cuestas Basálticas. O programa computacional usado para a geração e mani pulação de imagens (Sistemas de I nfor mações Geográficas) foi ol drisi for Windows, Eastman (1992), utilizando-se a estrutura raster.

Para definir a área a ser estudada e descrita, identificou-sea zona climática homogênea, ondeestá inserta a região de São Carlos, através da inter seção entre os mapas de isoterma anual e de deficiência hídrica anual gerados. Em seguida, essa zona climática foi sobreposta ao mapa geomorfológico gerado. A interseção de ambos foi admitida como a área com maior homogeneidade de características ambientais para o planejamento da atividade agrícola, denominada zona agroecológica. Pelo fato de as informações e estatísticas existentes para estudo de sistemas de produção encontrarem-se agrupadas de acordo com divisões administrativas, foi feita nova interseção da zona agroecológica, obtida com o mapa de divisão administrativa dos municípios da região de São Carlos. No mapa resultante, sel ecionaram-setodos os municípios com pel o menos $20 \%$ de sua área coincidente com a zona agroecológica. A região abrangida por esses municípios foi, finalmente, definida como a área de estudo destetrabal ho, a qual foi denominada dezona agroecoadministrativa de São Carlos.

Após essa fase, foram identificadas as unidades de mapeamento de solos ocorrentes na área de estudo, utilizando-se os mapas pedológicos do Estado de São Paulo. Para tanto, foram digitalizadas as quadrículas do IAC, na área coincidente com a zona agroecoadministrativa de São Carlos (Figura 1).

O mapa de unidades de mapeamento de solos gerado foi então reclassificado em dois novos mapas, sendo um somente de textura e outro de fertilidade. Quanto à fertilidade, os solos foram agrupados em três tipos: álicos, distróficos e eutróficos. J á o mapa detextura foi dividido em somente duas dasses: solos arenosos e argilosos, de acordo com a textura do Horizonte $A$. Os solos de textura média foram agrupados na categoria arenosos, e os de textura muito argilosa, na categoria argilosos.

Em seguida, foi feita uma interseção entre os mapas de textura e fertilidade, obtendo-se um mapa de zonas edáficas, em que são apresentadas as possíveis combinações entre álicos, distróficos e eutróficos versus arenosos e argilosos, formando, assim, a base para o planejamento agrícola e a sel eção de espécies a serem cultivadas na região.

Paral elamente, com base na literatura existente (Fancelli et al., 1985; Monteiro 1993; Wutke, 1993; e Primavesi et al., 1995), foram selecionadas espécies 
de adubo verde com exigências ecofisiológicas compatíveis com as características edafodimáticas da região amostrada. Posteriormente, em função da exigência em fertilidade, tolerância a alumínio e resistência a geada, as espécies sel ecionadas foram dassificadas em: exigentes, rústicas emuito rústicas.

Finalmente, realizou-se um cruzamento entre o banco de dados formado pel os grupos de espécies eo mapa das zonas edáficas anteriormente elaborado. O resultado desse cruzamento gerou um novo mapa com as zonas de cultivo, obtendo-se as áreas com maior aptidão edafoclimática para cada grupo de espécies.

\section{RESULTADOS E DISCUSSÃO}

De acordo com o método empregado neste trabal ho, a zona agroecoadministrativa da região de São Carlos éformada pel os municípios deAnalândia, I tirapina, Santa Maria da Serra, São Carlos, São Pedro eTorrinha, localizando-se entre as latitudes $21^{\circ} 32^{\prime} \mathrm{S}$ e $22^{\circ} 36^{\prime} \mathrm{S}$ e as longitudes $47^{\circ} 33^{\prime} \mathrm{W}$ e $48^{\circ} 18^{\prime} \mathrm{W}$, e ocupando uma área total de 286.824 ha. Situa-se na região central do Estado de São Paulo, fazendo parte da província geomorfológica das Cuestas Basálticas, posicionando-se em uma altitude da ordem de 800 a $900 \mathrm{~m}$. Nesse planalto, ocorrem as formações

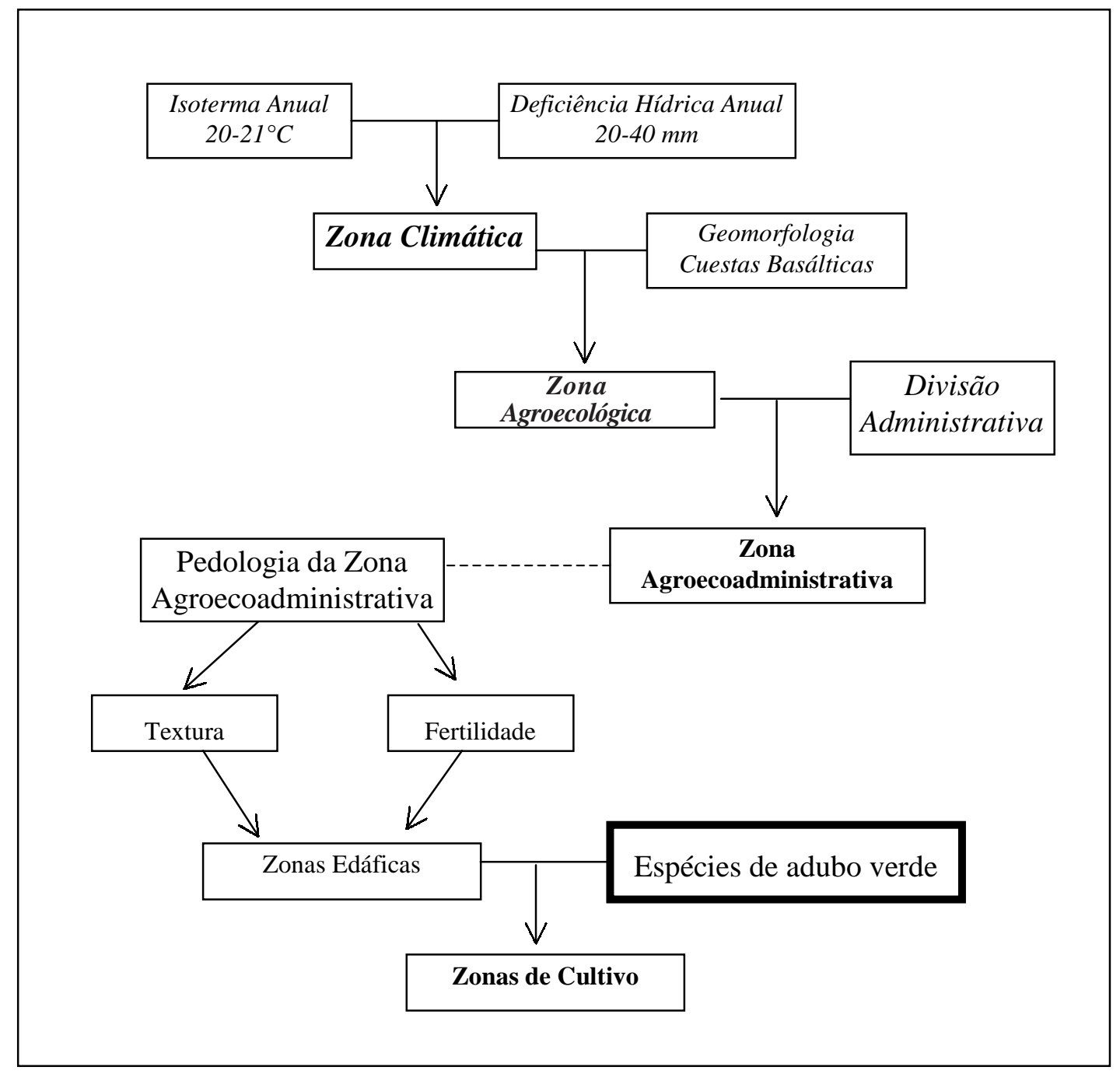

Mapas e imagens - mapas básicos em itálico

Bancos de dados

Figura 1. Fluxograma com as etapas da pesquisa. 
geológicas Botucatu (Grupo São Bento), Serra Geral (GrupoSãoBento), Bauru (Grupo Bauru) eformações superficiais (Cenozóico). A vegetação predominante é o cerrado.

O clima da região é classificado como Cwa segundo Koeppen, isto é, subtropical mesotérmico, úmido, com chuvas de verão e com estiagem branda no inverno. A estação chuvosa vai de outubro a março, e a estação seca, de abril a setembro. Há ocorrência esporádica de geadas. De acordo com Verdade et al. (1974), a área encontra-se na faixa da isoterma anual de 19 a $20^{\circ} \mathrm{C}$, estando a isoterma do mês mais frio (julho) entre 15 e 16ㅇ. A deficiência hídrica anual varia de 20 a $40 \mathrm{~mm}$, distribuindo-se em: 0-10 mm (abril-maio), 0-10 mm (junho-julho) e 20-40 mm (agosto-setembro).

A descrição dos solos da região encontra-se no quadro 1, onde são apresentadas as unidades de mapeamento existentes na zona agroecoadministrativa, assim como a área absoluta e relativa ocupada por cada unidade encontrada. Deve-selembrar que os solos de textura média foram enquadrados no grupo de solos de textura arenosa, justificandose, assim, a presença de latossolos arenosos.

Nota-sea predominância de L atossol os Vermel hoAmarel os e de areias quartzosas, ocupando $56 \%$ da área total. Em seguida, aparecem os Podzólicos Vermel ho-Amarelos com 13\%,e os litól i cos ocorrendo em 9\% da área total.

Quadro 1. Solos da Zona Agroecoadministrativa de São Carlos, área total e relativa de ocorrência(1)

\begin{tabular}{lcc}
\hline & \multicolumn{2}{c}{ Área } \\
\cline { 2 - 3 } & Total & Relativa \\
& & $\%$ \\
Latossolo Vermel ho-Amarelo a,s & 82.769 & 29,8 \\
Areia Quartzosa a,s & 54.464 & 19,6 \\
Litólicos e,r & 25.434 & 9,2 \\
Latossolo Roxo d,r & 21.746 & 7,8 \\
Latossolo Vermel ho-Amarelo a,r & 21.396 & 7,7 \\
Podzólico Vermel ho-Amarelo d,s & 20.493 & 7,4 \\
Podzólico Vermelho-Amarelo a,s & 16.192 & 5,8 \\
Latossolo Vermel ho-Escuro a,s & 10.463 & 3,8 \\
Hidromórficos & 9.042 & 3,3 \\
Latossol o Vermel ho-Escuro a,r & 7.700 & 2,8 \\
Latossolo Roxo e,r & 4.122 & 1,4 \\
Terra Roxa estruturada e, $r$ & 2.132 & 0,8 \\
Terra Roxa estruturada d,r & 1.205 & 0,4 \\
Podzólico Vermel ho-Escuro e,r & 112 & 0,1 \\
Total & 277.364 & 100,00 \\
\hline
\end{tabular}

(1) É válido esclarecer que a área total dos mapas pedológicos não coincide com a área da Zona Agroecoadministrativa em função da inexistência da quadrícula Botucatu, que complementaria a área ocupada pelos municípios de São Pedro, Torrinha e Santa Maria da Serra.

a - álico, d - distrófico e e - eutrófico; s - textura arenosa e $r$ - textura argilosa (texturas do Horizonte A).
Os solos hidromórficos foram desconsiderados para uso agrícola neste trabal ho, considerando sua localização em áreas alagadas e margens de rios. Ainda há muitas controvérsias sobre a utilização desse tipo de sol o e ecossistema e, segundo o Código Florestal (Lei 4.771), as várzeas são consideradas áreas de preservação permanente. Dessa forma, optou-se pela indicação preliminar dessas áreas como de proteção ambiental.

Analisando os mapas de textura e fertilidade, verificou-se a dominância de solos arenosos (78\%) contra a menor ocorrência de sol os argil osos (22\%). Por sua vez, $88 \%$ dos solos são de baixa fertilidade, sendo $72 \%$ álicos e $16 \%$ distróficos, ocorrendo $12 \%$ de solos eutróficos.

Os resultados do cruzamento entre os mapas de textura e fertilidade encontram-se na figura 1 e no quadro 2. A figura 1 apresenta o mapa com a distribuição geográfica das zonas edáficas obtidas na zona agroecoadminstrativa de São Carlos, e o quadro 2 mostra as áreas totais e rel ativas ocupadas por cada uma das zonas.

Nota-se o predomínio da Zona I, caracterizada pela ocorrência de sol os de textura arenosa e álicos, confirmando a teoria sobre solos de Cerrado de Ferraz (1987), que relata o predomínio de Areias Quartzosas e Latossolos álicos. O autor, porém, reforça que esta região apresenta grande potencial para o desenvolvimento da agricultura através do uso de técnicas compatíveis com as características naturais dessa área.

Após a análise edafoclimática, os critérios sugeridos para seleção de espécies a serem cultivadas na região devem considerar, de modo geral: i) dominância de sol os arenosos, ii) ocorrência de déficits hídricos, iii) possibilidade de controle de nematóides, iv) ocorrência de verões quentes e úmidos e invernos frios e secos, e v) ocorrência de geadas. Com relação à fertilidade do solo, devem-se considerar a baixa fertilidade natural do solo, a pequena disponibilidade de fósforo e matéria orgânica e o alto teor de alumínio.

Após análise dos trabalhos citados que descrevem a ecofisiologia de plantas com potencial para serem utilizadas como adubo verde, selecionaram-se as espécies relacionadas no quadro 3. Este quadro apresenta também as texturas preferenciais para desenvol vimento, exi gência em fertilidade, tolerância a alumínio, controle de nematói des e resistência à geada das espécies sel ecionadas.

Com o resultado do quadro 3, agruparam-se as espécies de acordo com suas exigências específicas. Assim, em função da exigência em fertilidade e tolerância ao alumínio, foram criados três grupos de espécies: muito rústicas, rústicas e exigentes, agrupadas da seguinte forma:

Grupol - Muito rústicas: Brachiaria, estil osantes, fejjãode-porco, guandu, mucuna-cinza e mucuna-preta. 
Quadro 2. Área total (ha) e relativa das zonas edáficas

\begin{tabular}{llrr}
\hline & & \multicolumn{2}{c}{ Área } \\
\cline { 3 - 4 } Zona & Classificação & Total & Relativa \\
\hline & & ha & $\%$ \\
I & Arenosa/álica & 163.888 & 61,1 \\
II & Arenosa/distrófica & 42.239 & 15,7 \\
III & Arenosa/eutrófica & 4.122 & 1,5 \\
IV & Argilosa/álica & 29.096 & 10,8 \\
V & Argilosa/distrófica & 1.205 & 0,4 \\
VI & Argilosa/eutrófica & 27.678 & 10,3 \\
\hline
\end{tabular}

Grupo II - Rústicas: cal opogônio, Crotalaria juncea, milheto, milho variedade, nabo forrageiro, soja e tremoço. GrupollI - Exigentes: centrosema, girassol, lab-lab, milho híbrido e soja perene (Figura 3).

Final mente, relacionaram-se esses grupos com as zonas edáficas obtidas, gerando um mapa final, onde se apresentam as zonas de cultivo de cada um dos grupos de espécies el aborados (Figura 2).

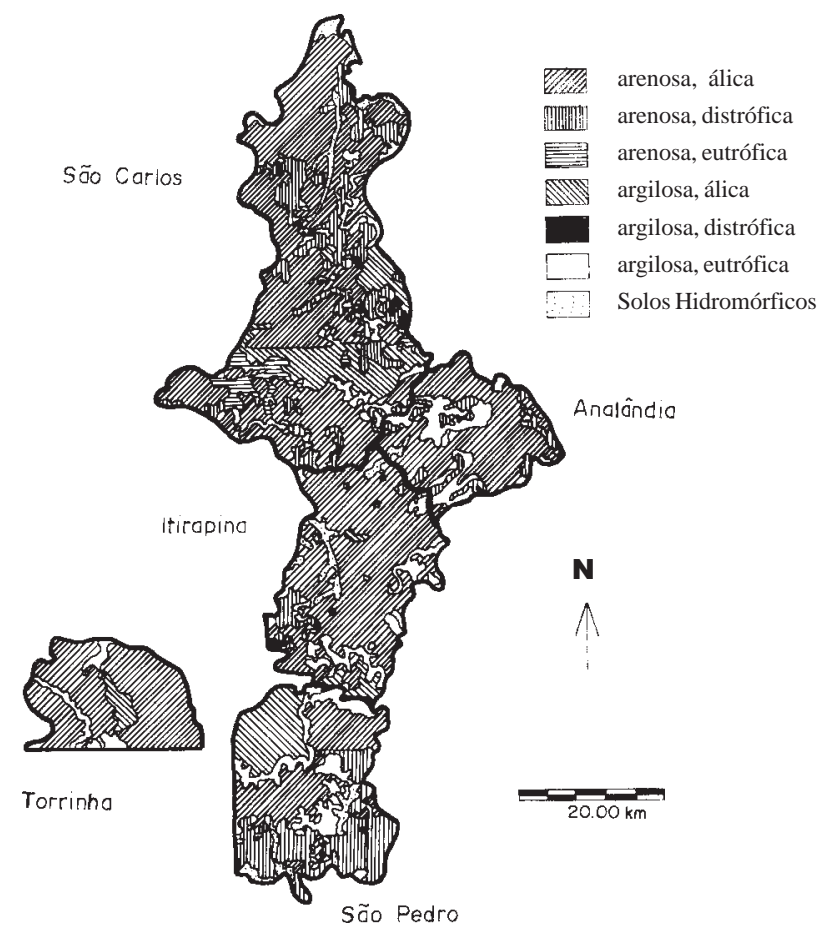

Figura 2. Zonas E dáficas da Zona Agroecoadministrativa de São Carlos.

Quadro 3. Espécies de adubo verde com potencial de utilização na zona agroecoadministrativa de São Carlos e suas texturas preferenciais, exigência em fertilidade, tolerância a alumínio, controle de nematóides e resistência à geada

\begin{tabular}{|c|c|c|c|c|c|}
\hline Espécie & $\begin{array}{c}\text { Textura } \\
\text { preferencial }\end{array}$ & $\begin{array}{c}\text { Exigência } \\
\text { em fertilidade }\end{array}$ & $\begin{array}{l}\text { Tolerância } \\
\text { a alumínio }\end{array}$ & $\begin{array}{c}\text { Controle } \\
\text { de nematóides }\end{array}$ & $\begin{array}{c}\text { Resistência } \\
\text { à geada }\end{array}$ \\
\hline \multicolumn{6}{|c|}{ Grupo I: Muito rústica } \\
\hline $\begin{array}{l}\text { Brachiaria } \\
\text { Estilosantes } \\
\text { Feijão-de-porco } \\
\text { Guandu } \\
\text { Mucuna-cinza } \\
\text { Mucuna-preta }\end{array}$ & $\begin{array}{l}\text { arenosa } \\
\text { arenosa } \\
\text { indiferente } \\
\text { indiferente } \\
\text { indiferente } \\
\text { indiferente }\end{array}$ & $\begin{array}{l}\text { baixa } \\
\text { baixa } \\
\text { baixa } \\
\text { baixa } \\
\text { baixa } \\
\text { baixa }\end{array}$ & $\begin{array}{l}\text { média } \\
\text { alta } \\
\text { alta } \\
\text { média } \\
\text { alta } \\
\text { alta }\end{array}$ & $\begin{array}{l}\text { - } \\
\text { médio } \\
\text { ruim } \\
\text { ruim } \\
\text { bom } \\
\text { bom }\end{array}$ & $\begin{array}{l}\text { ruim } \\
- \\
\text { ruim } \\
\text { moderada } \\
\text { ruim } \\
\text { ruim }\end{array}$ \\
\hline \multicolumn{6}{|l|}{ Grupo II : Rústica } \\
\hline $\begin{array}{l}\text { Calopogônio } \\
\text { Crotalaria juncea } \\
\text { Milheto } \\
\text { Milho variedade } \\
\text { Nabo forrageiro } \\
\text { Soja } \\
\text { Tremoço }\end{array}$ & $\begin{array}{l}\text { indiferente } \\
\text { arenosa } \\
\text { indiferente } \\
\text { indiferente } \\
\text { indiferente } \\
\text { indiferente } \\
\text { indiferente }\end{array}$ & $\begin{array}{l}\text { baixa } \\
\text { média } \\
\text { baixa } \\
\text { média } \\
\text { média } \\
\text { média } \\
\text { média }\end{array}$ & $\begin{array}{l}\text { média } \\
\text { média } \\
\text { média } \\
\text { média } \\
\text { média } \\
\text { baixa } \\
\text { média }\end{array}$ & $\begin{array}{l}- \\
\text { bom } \\
- \\
- \\
- \\
- \\
-\end{array}$ & $\begin{array}{l}\text { ruim } \\
\text { ruim } \\
\text { boa } \\
\text { ruim } \\
\text { boa } \\
\text { ruim } \\
\text { boa }\end{array}$ \\
\hline \multicolumn{6}{|l|}{ Grupo III : Exigentes } \\
\hline $\begin{array}{l}\text { Centrosema } \\
\text { Girassol } \\
\text { Lab-lab } \\
\text { Milho híbrido } \\
\text { Soja perene }\end{array}$ & $\begin{array}{l}\text { indiferente } \\
\text { indiferente } \\
\text { indiferente } \\
\text { indiferente } \\
\text { indiferente }\end{array}$ & $\begin{array}{l}\text { média a alta } \\
\text { alta } \\
\text { alta } \\
\text { alta } \\
\text { alta }\end{array}$ & $\begin{array}{l}\text { média } \\
\text { baixa } \\
\text { baixa } \\
\text { baixa } \\
\text { baixa }\end{array}$ & $\begin{array}{l}\text { médio } \\
\text { - } \\
\text { ruim } \\
\text { - }\end{array}$ & $\begin{array}{l}\text { ruim } \\
\text { boa } \\
\text { ruim } \\
\text { ruim } \\
\text { moderada }\end{array}$ \\
\hline
\end{tabular}

Fonte: Adaptado de Calegari (1993), Wutke (1993) e Monteiro (1993).

“-" sem informação. 


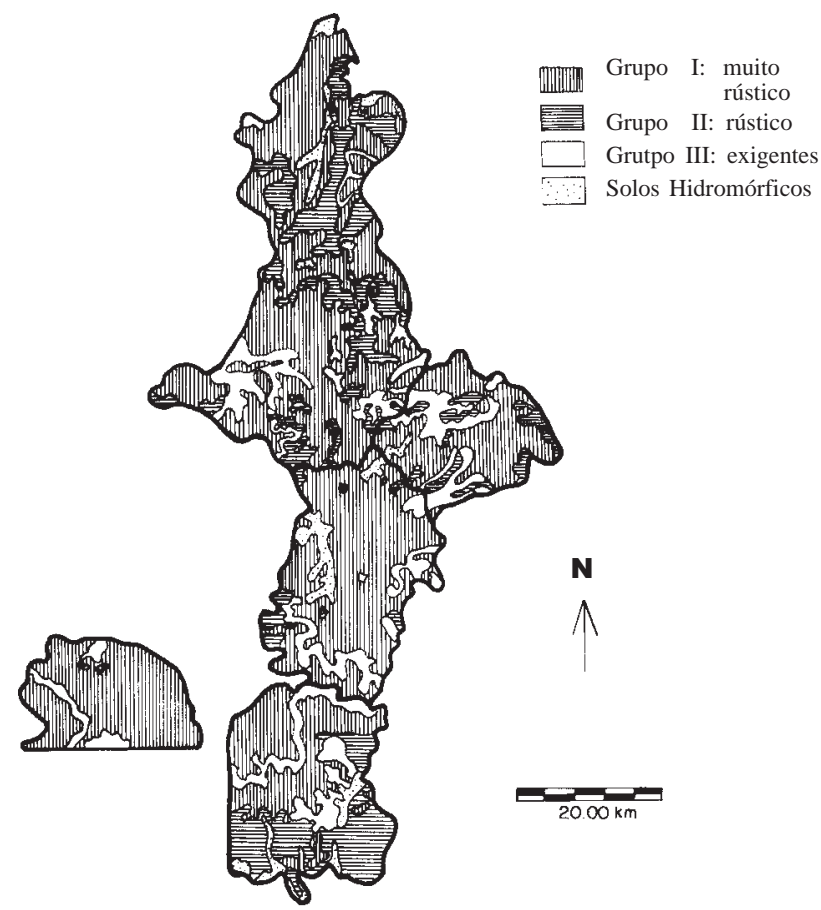

Figura 3. Zonas de cultivo dos grupos de espécies selecionadas para adubação verde na Zona Agroecoadministrativa de São Carlos.

Dessa forma, pode-se inferir que as plantas citadas neste trabalho têm potencial para serem utilizadas como adubo verde na região estudada, de acordo com os objetivos propostos inicialmente. Devem, entretanto, passar por um processo de experimentação no campo, para a validação dos resultados prospectivos gerados no presente trabalho.

\section{CONCLUSÕES}

1. A adubação verde é uma técnica de utilização viável nos agroecossistemas da região de São Carlos, havendo espécies de plantas de adubo verde com exigências ecofisiológicas compatíveis com as distintas zonas edafocl imáticas da região estudada.

2. A realização de estudos prospectivos, como ilustrados nestetrabal ho, pode cumprir importante papel na pesquisa agronômica, à medida que proporciona economia de tempo e recursos e orienta o planejamentoe execução objetiva de experimentos.

\section{AGRADE CIME NTOS}

Ao Prof. Dr. Marcelo Pereira de Souza (SHS/ EESC/USP), pelos comentários, sugestões e orientação no uso do sistema de informações geográficas. Ao Dr. Odo Primavesi (CPPSE/ EMBRAPA), pelas contribuições teóricas e práticas para a realização deste trabal ho. À doutoranda em Solos e Nutrição de Plantas da ESALQ, Simone Beatriz Lima Ranieri, pela revisão dos originais. Aos três revisores anônimos da RBCS, por suas contribuições para este artigo.

\section{LITERATURA CITADA}

BULISANI, E.A. \& ROSTON, A.J . Leguminosas: adubação verde e rotação de culturas. In: INSTITUTO AGRONÔMICO DE CAMPINAS. Curso sobre adubação verde no Instituto Agronômico, 1. Campinas, 1993. p.13-16.

CALEGARI, A. Aspectos gerais da adubação verde. In: COSTA, M.B.B., coord. Adubação verde no sul do Brasil. Rio de J aneiro, Pta/Fase, 1993. p.1-55.

CAMARGO, A.P.; PINTO, H.S.; PEDRO J R.,M.J .; BRUNINI, O.; ALFONSI, R.R. \& ORTOLANI, A.A. Aptidão climática de culturas agrícolas. In: VERDADE, F.C., coord. Zoneamento agrícola do Estado de São Paulo. São Paulo, Governo do Estado de São Paulo, Secretaria da Agricultura. 1974. v.1. p.109.

EASTMAN, J . R. I drisi- user's guide. Worcester, Clark University, 1992. 229p.

ELLIOT, E.T. \& COLE,C.V. A perspective on agroecossystem science. Ecology, 70:1597-1602, 1989.

FANCELLI, A.L.; TORRADO, P.V. \& MACHADO, J . Atualização em plantio direto. Campinas, Fundação Cargill, 1985. 343p.

FERRAZ, E.C. A ecofisiologia vegetal e a produção de alimentos no Cerrado. In: CASTRO, P.R.C. E cofisiologia da produção agrícola. Piracicaba, POTAFOS, 1987. p.101-111.

GONÇALVES, A.R.L.; LORANDI, R.; ELLERT,N. \& GONÇALVES, .M.M. Geologia ambiental da área de São Carlos. In: SEMINÁRIO REGIONAL DE ECOLOGIA, 6., São Carlos, 1991. Anais. São Carlos, 1991. p.565-579.

HANSEN, J.W. Is agricultural sustainability a useful concept? Agric. Syst., 50:117-143, 1996.

MONTEIRO, A.R. Controle de nematóides por adubo verde. In: INSTITUTO AGRONÔMICO DE CAMPINAS. Cursosobre adubação verde no Instituto Agronômico, 1. Campinas, 1993. p.109-121.

PINTO, L.F.G. Estudo prospectivo visando o planejamento do uso da adubação verde nos agroecossistemas de São Carlos, SP. São Carlos, Universidade de São Paulo, 1996. 87p. (Tese de Mestrado).

PINTO, L.F.G. \& CRESTANA S. Planejamento do uso da adubação verde nos agroecossitemas de São Carlos, SP. In: CONGRESSO LATINOAMERICANO DE CIÊNCIA DO SOLO, 25., Águas de Lindóia, 1996. Resumos. Piracicaba, Sociedade Brasileira de Ciência do Solo, 1996. (CD-Rom) 
PRIMAVESI, O.; PRIMAVESI, A.C. \& NOVAES, N.J . Espécies vegetais para produção de cobertura morta de solo, em plantio no outono, sem irrigação, na região de São Carlos, SP. II-Período 1994. In: CONGRESSO BRASILEIRO DE CIÊNCIA DO SOLO, 25, Viçosa, 1995. Resumos expandidos. Viçosa, Sociedade Brasileira de Ciência do Solo, 1995. p.2002-2004.

STAR, J \& ESTES, J . Geografic I nformation Systems. New J ersey, Prentice-Hall, 1990. 303p.
VERDADE, F.C. Coord. Zoneamento agrícola do Estado de São Paulo. São Paulo, Governo do Estado de São PauloSecretaria da Agricultura, 1974. v.1.

WUTKE, E.B. Adubação verde: manejo de fitomassa e espécies utilizadas no Estado de São Paulo. In: INSTITUTO AGRONÔMICO DE CAMPINAS. Curso sobre adubação verde no Instituto Agronômico, 1. Campinas, 1993. p.1729. 